\title{
P02.152. Is electro-acupuncture beneficial for overall quality of life improvement of undergraduates in depressive states? A pragmatic controlled trial
}

\author{
W Zhang ${ }^{*}$, T Guo, H Zhang, W Ma \\ From International Research Congress on Integrative Medicine and Health 2012 \\ Portland, Oregon, USA. 15-18 May 2012
}

\section{Purpose}

To assess the efficacy of electro-acupuncture on quality of life improvement of undergraduates in depressive states.

\section{Methods}

Fifty undergraduates in depressive states (CES-D score $\geq 16$, HAMD score $\geq 7,<17$ ) were assigned to 4 groups based on intervention preference in a pragmatic trial. Electro-acupuncture, cognitive behavior therapy (CBT), and a combined intervention of electro-acupuncture and CBT were implemented as interventions. A rejected intervention group in which no intervention was practiced was considered as a control condition. The electroacupuncture implemented traditional Chinese medicine (TCM)-style acupuncture. The CBT is practiced as 8 sessions of group counseling (1 time/week). Each 8-week course of electro-acupuncture consisted of 16 sessions (2 times/week) in the clinic of Beijing University of Traditional Chinese Medicine. The combined intervention consisted of 16 sessions of electro-acupuncture (2 times/ week) and 8 sessions of CBT (1 time/week) in an 8-week course. WHOQOL-BREF was evaluated at baseline and 8 weeks after interventions.

\section{Results}

Two subjects terminated interventions before the completion of the 8-week intervention. Intention to treat and per protocol analyses were applied but there were no differences shown. After 8 weeks, the rejected intervention group and CBT group showed no significant

Beijing University of Traditional Chinese Medicine, Beijing, China difference $(p>0.05)$, and although the score of electroacupuncture intervention and combined intervention participants in overall QOL were significantly improved $(p<0.05)$, no evidence of a differential improvement of electro-acupuncture intervention over combined intervention was found $(\mathrm{p}>0.05)$.

\section{Conclusion}

Electro-acupuncture showed a beneficial advantage in overall QOL improvement of undergraduates in depression states.

Published: 12 June 2012

doi:10.1186/1472-6882-12-S1-P208

Cite this article as: Zhang et al:: P02.152. Is electro-acupuncture beneficial for overall quality of life improvement of undergraduates in depressive states? A pragmatic controlled trial. BMC Complementary and Alternative Medicine 2012 12(Suppl 1):P208.

Submit your next manuscript to BioMed Central and take full advantage of:

- Convenient online submission

- Thorough peer review

- No space constraints or color figure charges

- Immediate publication on acceptance

- Inclusion in PubMed, CAS, Scopus and Google Scholar

- Research which is freely available for redistribution 